\title{
Secondary Sponsor
}

National Cancer Institute

\section{Source}

National Cancer Institute. Secondary Sponsor. NCI Thesaurus. Code C142679.

Additional individuals, organizations or other legal persons, if any, that have agreed with the primary sponsor to take on sponsorship responsibilities. (WHO) 